\title{
LA SIERRA DE CARTAGENA-LA UNIÓN (MURCIA): UN EJEMPLO DE ACTIVIDAD TURÍSTICA A TRAVÉS DEL PATRIMONIO MINERO
}

\author{
Francisco José Morales Yago ${ }^{1}$ \\ Universidad Nacional de Educación a Distancia
}

\section{RESUMEN}

El cese final en el año 1991 de la actividad minera en la Sierra de Cartagena-La Unión en la Región de Murcia supuso para esta comarca el inicio de un gran declive económico que no ha encontrado respuesta hasta tiempos recientes, en donde la iniciativa para la puesta en valor del importante legado minero-industrial está sirviendo de base en la creación de un proyecto turístico complementario al tradicional de sol y playa ubicado en La Manga del Mar Menor y demás espacios litorales. El análisis DAFO incluido como metodología principal de este trabajo permitirá a través de la participación de distintos colectivos conocer y analizar el presente así como la proyección de futuro de esta nueva actividad que potencialmente supondrá un importante cambio en la actividad socioeconómica de la comarca y por consiguiente de sus habitantes.

Palabras Clave: Minería; Turismo; Paisaje, Patrimonio, Industria; Cartagena; La Unión

\section{THE MOUNTAIN RANGE OF CARTAGENA-LA UNION (MURCIA): AN EXAMPLE OF TOURIST ACTIVITY THROUGH THE MINING HERITAGE}

\section{ABSTRACT}

The final cessation in 1991 of mining in the Sierra de Cartagena-La Union Murcia region earned it the beginning of a major economic downturn has not answered until recent times, where the initiative for the enhancement of important mining-industrial legacy is now the basis for the creation of a tourism project complementary to traditional sun and beach located in La Manga del Mar Menor. The SWOT analysis included as the main methodology of this work will allow through the participation of different groups understand and analyze the present and the future prospects of this new activity that potentially represent a major change in the socioeconomic activity of the region and therefore of its inhabitants.

Key words: Mining; Tourism; Landscape, heritage, industry; Cartagena; The Union

Fecha de recepción: 31 de enero de 2015. Fecha de aceptación: 27 de marzo de 2015.

${ }^{1}$ fjmorales@ geo.uned.es C/Senda del Rey n ${ }^{\circ}$ 7. 28040 Madrid 


\section{INTRODUCCIÓN}

A partir de la segunda mitad del siglo XX, se produjo una importante crisis en la minería española, la falta de productividad frente a la competencia de otros espacios emergentes a nivel mundial desembocaron en el cierre progresivo de la mayor parte de las cuencas mineras españolas (GARCIA et al., 2013). De hecho estos paisajes perdieron su función extractiva pasando a una progresiva degradación ambiental sin precedentes.

Tras varias décadas de indefinición, sin saber muy bien qué hacer con estos espacios, comenzó el interés por la puesta en valor como un patrimonio material de interés cultural y turístico, ayuntamientos, diputaciones provinciales y las propias comunidades autónomas inician tareas de catalogación y planes de protección de estos espacios, aunque en muchos casos la degradación había alcanzado niveles que hacían muy complicada una recuperación integral debido a la magnitud económica que implicaban estas actuaciones, no obstante a través de programas europeos LEADER II y LEADER + o PRODER I y II se iniciaron estas tareas que todavía en la actualidad permanecen en pleno desarrollo. De hecho este nuevo turismo industrial es un elemento que tiene como objetivo promocionar y desarrollar espacios con una importante potencialidad, a falta de la puesta en valor de los recursos existentes (PRAT I FORGA, 2014) así como una importante alternativa muy novedosa que permite conocer nuevos espacios con un estética peculiar y diferenciada (LLURDÉS I COIT, 1994) y la evolución técnica y el progreso de una producción industrial iniciada a finales del siglo XVIII, pero prolongada hasta el presente (HUDSON., 1983)

En la Región de Murcia encontramos dos espacios catalogados como "Bien de Interés Cultural" de tipo industrial, se trata del embarcadero del mineral del Hornillo en Águilas (Decreto 316/2009, de 25 de septiembre). Esta peculiar estructura metálica fue construida por la Compañía Británica de Ferrocarriles del Sureste (GRRS) por encargo de The Hornillo Company Limited para dar salida marítima a los minerales de hierro de Las Menas y de otros cotos mineros de la Sierra de Los Filabres. Este cargadero fue inaugurado en 1903. Tiene una longitud de 168 metros y una altura sobre el mar de casi 13 metros. Dispone de tres vías para la circulación de vagonetas y maniobras, y de vertederos a ambos lados del muelle. Existía un ferrocarril desde las minas hasta el cargadero que perduró hasta la década de los años 60 del siglo XX. El otro es el paisaje minero de La Unión-Cartagena objeto de nuestro trabajo, aunque también queremos destacar el espacio del Arsenal de Cartagena, lugar que todavía no ha encontrado la fórmula, a pesar de disponer de un rico legado patrimonial (CARCELÉN GONZÁLEZ, 2013) y que actualmente se encuentra en un limbo legal por no haber sido declarado Bien de interés cultural por el Ministerio de Cultura, que es quien tiene la competencia de su protección; según la Ley 16/85 y por tratarse de una instalación no transferida a la Región de Murcia, vinculada a los Ministerios de Defensa e Industria.

El Decreto n ${ }^{\circ}$ 93/2009, de 30 de abril, del Consejo de Gobierno de la Comunidad Autónoma de la Región de Murcia, declaró bien de interés cultural, con la categoría de sitio histórico la Sierra Minera de Cartagena y la Unión (Murcia). Dicha declaración ha supuesto un punto de inflexión y puesta en funcionamiento para la progresiva recuperación de este espacio singular de la Región de Murcia.

\section{EL PATRIMONIO MINERO COMO APUESTA TURÍSTICA}

La industria ha sido la gran responsable del desarrollo económico y social que disfrutan las sociedades avanzadas. Los restos o manifestaciones materiales de dicho desarrollo están todavía presentes en el paisaje (PARDO ABAD, 2008). La huella de esa actividad industrial representa la aparición en muchas ocasiones de "paisajes abandonados" que recuerdan el esfuerzo colectivo de épocas pasadas por iniciar, mantener y finalmente abandonar una actividad económica que suponía casi de forma unitaria el medio de vida de los habitantes de ese espacio. A medida que se hicieron evidentes los efectos de la crisis y el declive industrial fue madurando 
una sólida corriente de opinión y de pensamiento sensible (BENITO DEL POZO, 2002) con los restos de las industrias abandonadas se plantearon al menos dos opciones, la primera suprimir, borrando cualquier resto de espacio industrial y adaptando otros usos como el residencial; la segunda la idea de proteger y conservar, en definitiva poner en valor estos espacios como un legado de actividades abandonadas para pasar a otras, generalmente y para el caso de la minería como espacios temáticos para el turismo y la visita cultural-lúdica. Elementos como la propia morfología del espacio: galerías, pozos o maquinaria industrial que daría paso a una verdadera arqueología industrial a través de los más variados mecanismos que suponían ver in situ el funcionamiento de los mismos o el traslado como auténticas piezas de museo a espacios programados para ello.

Uno de los primeros trabajos relacionados con la rehabilitación del patrimonio minero de las sierras de La Unión-Cartagena fue el desarrollo por ANDRÉS SARASA, indicaba las dificultades esencialmente económicas que supone esta puesta en valor, y la arriesgada idea del turismo como prácticamente el único motor de desarrollo local tras el declive económico por el cese de actividad minera. Relataba los planes de llevar a cabo la construcción de grandes complejos residenciales-hoteleros con base principal en la bahía de Portmán tras una supuesta regeneración. Los deseos de un enriquecimiento rápido por parte de las promotoras no deben ser el elemento base para la regeneración del espacio puesto que este proceso podrían tener graves consecuencias medioambientales debido a la tendencia especulativa ante este tipo de iniciativas, tal como ha ocurrido durante décadas en el vecino espacio de La Manga del Mar Menor (MORALES YAGO, 2013) y es todo un referente de competitividad ante este incipiente turismo de tipo cultural, lo que podría enfocarse más hacia un carácter de complementariedad que contribuye a romper la tradicional estacionalidad del turismo existente en este espacio desde hace décadas. También el turismo industrial y de minería se presenta como una importante alternativa casi desconocida ante el tradicional de masas o sol y playa (LLURDÉS I COIT, 1994), de hecho con la llegada del turismo industrial se confirma la iniciativa de una generación, la nuestra, que comienza a valorar como bienes patrimoniales una serie de objetos utilizados prácticamente por nosotros mismos o nuestros antepasado inmediatos (CASANELLES Y FERNÁNDEZ., 1994)

En el trabajo de VALENZUELA RUBIO, señala como ejemplo de valorización turística del patrimonio minero en entornos rurales actuaciones en las comunidades autónomas de CastillaLeón con cuatro actuaciones en la montaña Palentina y el Bierzo; en Aragón con tres actuaciones en Andorra-Sierra de Arcos, Cuencas Mineras de Teruel y Jiloca, finalmente en las minas de Alquife en la comarca granadina del Marquesado de Zenete (hoya de Guadix) que fue la mina de hierro más grande de Europa en el momento de su cierre (1997), señala que la conservación del patrimonio minero es siempre una cuestión problemática puesto que la mayoría de estos espacios llevan tiempo abandonados y por tanto con alto grado de deterioro, aunque excepcionalmente algunos cierres de instalaciones como es el caso de Almadén (Ciudad Real) clausuradas en el año 2002 supuso una continuidad en el proceso de rehabilitación con fines esencialmente turísticos (CAÑIZARES RUIZ, 2011) y educativos, para ello se creó el Parque Minero de Almadén en donde afortunadamente se han recuperado numerosos edificios y centros expositivo-culturales como la visita a la propia mina, museo del mercurio, museo de la Minería, Real Hospital de Mineros, etc.). También cabe destacar la mejora de las infraestructuras como acceso a los espacios por ejemplo la puesta en marcha de trenes de la época, creación de centros de interpretación o vías verdes para cicloturismo y senderismo.

Los trabajos de PARDO ABAD, 1990-2013 constituyen un referente en la bibliografía española dedicada al patrimonio industrial, destacando respecto a la minería el esfuerzo por recuperar estos espacios para la mejora del territorio y el nacimiento de la actividad turística en los parques mineros de Riotinto, Nerva y El Campillo en Huelva en 1992 y el parque minero de Almadén (Ciudad Real) a partir de 2004. La promoción del turismo ha experimentado un crecimiento constante lo que unido a la puesta en marcha del Plan Nacional de Patrimonio industrial y la celebración de eventos y congreso dedicados a esta temática auguran un producto 
turístico novedoso y atractivo, incluso experiencial y emotivo como por ejemplo el recorrido en tren en Ríotinto (CAÑIZARES RUIZ, 2011).

Precisamente, señalamos el parque minero de Ríotinto como el más importante y referente actual del territorio nacional, (GARCÍA et al., 2013) relatan en su trabajo como la recuperación tras el desmantelamiento industrial ha supuesto para esta comarca el nacimiento de una actividad turística sin precedentes que abarca siete municipios y una media anual que ha llegado a casi los 70.000 visitantes en el año 2014, con un total de 19 establecimientos en régimen de alojamiento, 180 habitaciones y 586 plazas.

Finalmente, es importante destacar los trabajos de CAÑIZARES RUIZ, 1998-2011 en donde realiza una importante síntesis sobre los espacios mineros puestos en valor, deteniéndose más profusamente en Riotinto (Hueva), Almadén (Ciudad Real), Andorra-Sierra de Arcos MWINAS en Teruel (Aragón) y el caso que más nos interesa: La Unión-Cartagena (Murcia), en donde incide en el amplio patrimonio material existente: "más de $4.000 \mathrm{~m}^{2}$ de galerías subterráneas en la Mina Agrupa Vicenta rehabilitada para la visita a 80 metros de profundidad, el pequeño recorrido en tren minero por parte de la Sierra (concretamente por la Carretera del 33 que unía Portmán y La Unión), desde el que se observa el Lavadero de la Mina Remunerada las Tolvas de la Mina Pablo y Virginia, el antiguo Polvorín, actualmente convertido en capilla; el Serpentín de la Fundición de Plomo Trinidad de Rentero; un Horno de Tostación rehabilitado. Además, la visita al Parque Minero se completa, en otros lugares, con la que se puede realizar al Centro de Interpretación Mina "Las Matildes" y el museo minero en la propia ciudad de La Unión inaugurado en 2001, tras la restauración del Antiguo Liceo de los mineros construido en 1901.En relación al patrimonio inmaterial referencia la importancia de un evento que se realiza periódicamente desde 1961 como es el Festival Internacional del Cante de las Minas de la Unión.

FigURAS 1 y 2

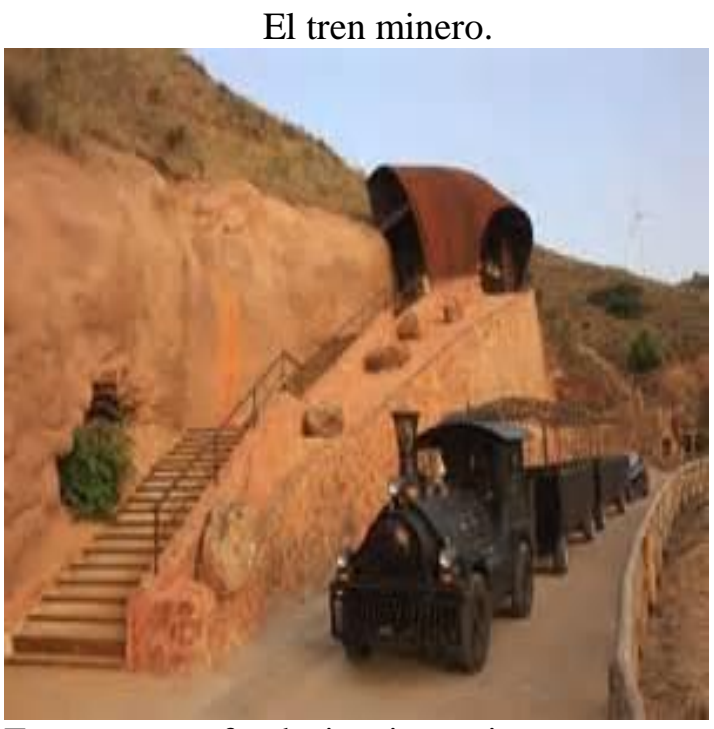

Fuente. www.fundacionsierraminera.org
Jornadas Turísticas en Portmán.

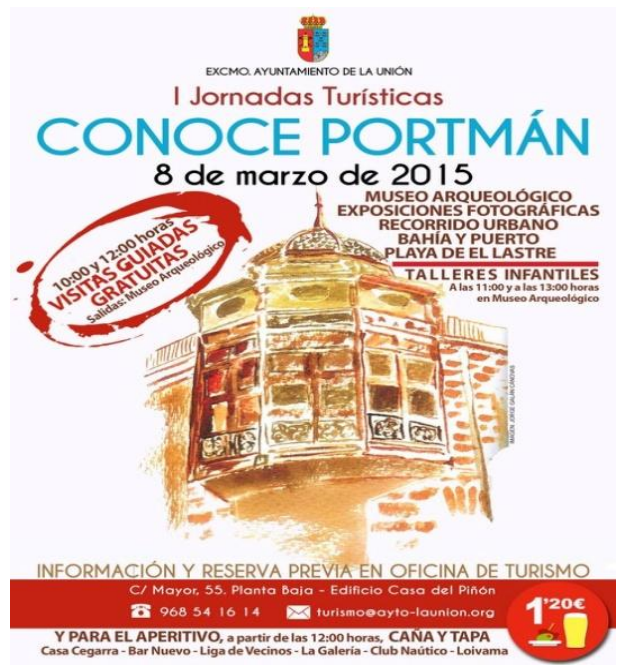

Fuente. Ayuntamiento La Unión 2015

\section{HIPÓTESIS Y OBJETIVOS DEL TRABAJO}

El objetivo general de este trabajo se podría sintetizar en una aproximación al conocimiento de la Sierra Minera de Cartagena-La Unión como un ejemplo significativo de un espacio en donde un plan de dinamización turística puede ayudar a restaurar este espacio para el uso turístico, a través de la recuperación y puesta en valor del patrimonio minero existente desde hace décadas. 
Este objetivo general se podría explicar en al menos cinco objetivos específicos:

a) Analizar la evolución de la actividad minera desde su máximo apogeo al cierre total de las minas por falta de competitividad.

Este objetivo estudiará el nacimiento de la actividad minera desde época romana hasta la década de los años 80 del pasado siglo XX. Muchas han sido las vicisitudes por las que ha pasado este espacio debidas a la extracción de mineral.

b) Mostrar las actuaciones llevadas a cabo para la recuperación y puesta en valor del patrimonio minero como un patrimonio cultural relevante.

La aparición del consorcio "Sierra Minera" y una serie de proyectos europeos, regionales y locales han hecho posible la organización del espacio de la sierran minera de La UniónCartagena en función de un patrimonio cultural y ambiental que aspira a convertirse es un gran museo que ocupa la mayor parte del espacio utilizado para la extracción y transporte del mineral.

c) Conocer las estrategias que buscan el desarrollo de un turismo sostenible

El espacio objeto de estudio debido a la acción humana se encuentra muy degradado, de hecho los depósitos de estériles y edificaciones en ruinas necesitan de grandes inversiones para que el aspecto de paisaje lunar que presenta este espacio pueda volver a restablecerse.

d) Establecer a través del análisis DAFO un conocimiento profundo de las características actuales de la actividad turística

e) Proponer ideas y actuaciones que ayuden a mejorar los puntos débiles detectados, así como la valoración de las iniciativas que ayuden ante las posibles amenazas que aparecen en el horizonte ante este tipo de turismo.

\section{METODOLOGÍA}

En este trabajo de investigación se ha empleado una metodología cualitativa para ello se diseñó una entrevista en profundidad a personas de relevancia que por sus circunstancias conocen y han trabajado este espacio geográfico. La técnica de la triangulación, la cual tiene una estrecha relación con la metodología cualitativa, será puesta en práctica desde dos de sus tipos: la triangulación de fuentes, en tanto la posibilidad de contrastar la información con diversos elementos (cuestionarios, entrevistas, etc.); y triangulación metodológica, por el método de obtención de dicha información. Destacaremos que, aunque la técnica empleada para los cuestionarios será en algún caso cuantitativa, la forma de analizar los resultados de los mismos será de forma cualitativa.

También se llevó a cabo una búsqueda bibliográfica de trabajos que pudieran estar relacionados con el área de estudio, entre los que podemos destacar dos fuentes básicas; la primera editadas por la Consejería de Turismo y Ordenación del Territorio de la Región de Murcia en la cual se establecía un "Plan de dinamización turística de la Sierra Minera de La Unión y Cartagena" y la segunda editada por la Fundación Sierra Minera denominada: "Estrategias para el desarrollo de un turismo sostenible en la Sierra Minera de Cartagena-La Unión" en el marco de las VI Jornadas sobre alternativa de Desarrollo en Comarcas Mineras.

Finalmente, a modo de síntesis tras el vaciado de las entrevistas y aportaciones de la bibliografía consultada así como la propia visita de campo se elaboró a través de la metodología DAFO un diagnóstico de la situación actual de este espacio en relación a su futuro turístico a través de la puesta en valor de sus recursos derivados de la antigua actividad minera y de los elementos como un paisaje cultural testigo de dicha actividad.

El análisis DAFO es una herramienta eficaz para el análisis de estudio de la situación de una empresa o un proyecto, analizando sus características internas (Debilidades y Fortalezas) y su situación externa (Amenazas y Oportunidades) en una matriz cuadrada. Proviene de las siglas en ingles SWOT (Strengths, Weaknesses, Opportunities y Threats). Es una herramienta para conocer la situación real en que se encuentra una organización, empresa o proyecto, y planear una estrategia de futuro. También permite la participación de distintos grupos de interés, 
ya que los participantes en las entrevistas son expertos o conocedores de la investigación llevada a cabo, lo que indica suficientes garantías de fiabilidad en las respuestas, y ello se incrementa con las respuestas llegan a un índice de saturación alto (por encima del 90\% de coincidencias)

A continuación presentamos la matriz que explicará el trabajo realizado a continuación.

\begin{tabular}{|l|l|l|}
\hline Análisis DAFO & FORTALEZAS & DEBILIDADES \\
\hline Análisis Interno & & \\
\hline & OPORTUNIDADES & AMENAZAS \\
\hline Análisis Externo & & \\
\hline
\end{tabular}

De la combinación de fortalezas con oportunidades surgen las potencialidades, las cuales señalan las líneas de acción más prometedoras para la organización. Las limitaciones, determinadas por una combinación de debilidades y amenazas, colocan una seria advertencia.

Mientras que los riesgos (combinación de fortalezas y amenazas) y los desafíos (combinación de debilidades y oportunidades), determinados por su correspondiente combinación de factores, exigirán una cuidadosa consideración a la hora de marcar el rumbo que la organización deberá asumir hacia el futuro deseable.

Una vez finalizados los análisis parciales (definidos los objetivos sobre el que se desarrolla el estudio y realización del trabajo de campo para conocer la realidad de los centros educativos sobre el que vamos a hacer dicho estudio), éstos permitirán realizar un diagnóstico de las debilidades, amenazas, fortalezas y oportunidades para, a continuación, y en función de este análisis, establecer unos objetivos, proponer diferentes estrategias de desarrollo capaces de superar los condicionantes identificados y alcanzar los objetivos de conocimiento del modelo de desarrollo turístico minero en La Unión-Cartagena. El análisis interno (puntos fuertes y débiles) examina en profundidad cada uno de los componentes que configuran las características internas de la puesta en valor de las instalaciones mineras con el propósito de identificar puntos fuertes y débiles en la organización de las mismas, la realización de nuevos proyectos o el rendimiento e cuanto a visitas existentes.

El análisis externo, por su parte, analiza la situación y las perspectivas del entorno en general para identificar y evaluar las variables que pueden constituir oportunidades o amenazas para el desarrollo de este modelo turístico. Éste debe tener en cuenta la situación socioeconómica de los visitantes, las políticas locales, regionales y nacionales así como el contexto del mundo global en que se desarrolla la economía turística del siglo XXI.

\section{Muestra}

Para la recogida de información se acudió a personas de fácil acceso de los centros en los que se habían aplicado los cuestionarios. Se considera que las personas seleccionadas cuentan con la suficiente formación y experiencia, por tanto se utilizó un criterio de selección de expertos, de personas que conocieran bien el espacio y la temática estudiada. A lo largo de las entrevistas, se crearon momentos de gran interacción entre el entrevistador y los entrevistados; a través de un cuestionario estructurado pero abierto a matizaciones, se recogió la información de forma transversal, es decir: recogida de una sola vez con el objetivo de estudiar fenómenos presentes en el momento de realización de la encuesta, lo que permitió un estudio tanto descriptico como analítico, obteniendo estimaciones generales de las variables, comparaciones entre subgrupos (profesores de universidad, directivos de empresas, autoridades locales, técnicos de turismo, etc.) y relaciones entre variables. Las entrevistas se realizaron a personas representantes de los diversos colectivos de los que obtuvimos una gran cantidad de información cualitativa. Del mismo modo, se buscaron personas relacionadas con el entorno que presentaban experiencias y una opinión fundamentada sobre el tema objeto de investigación. Se asignó un código a cada una de las personas entrevistas de tal forma que de forma fácil se pudiera identificar las 
opiniones de cada uno de los participantes. La composición queda recogida en la tabla número 1 .

TABLA 1

Muestra seleccionada en las entrevistas.

\begin{tabular}{|l|l|l|}
\hline Colectivo & $\mathbf{N}^{\mathbf{0}}$ entrevistas & CÓDIGO \\
\hline Profesorado UNED de Cartagena & 2 & UN1-UN2 \\
\hline Miembros de la Asociación Fundación Minera & 2 & FS1-FS2 \\
\hline Profesorado Universidad Politécnica Cartagena & 2 & UP1-UP2 \\
\hline Técnicos de turismo Ayuntamiento de La Unión & 3 & AY1-AY3 \\
\hline Miembros de Sindicatos actividad turística & 2 & SI1-SI2 \\
\hline Miembros de Patronales de Hostelería & 2 & PH1-PH2 \\
\hline Responsables de la Administración Autonómica & 2 & AD1-AD2 \\
\hline
\end{tabular}

En total fueron concertadas veinte entrevistas; conviene dejar constancia que la mayoría de las entrevistas realizadas fueron atendidas por los consultados, también a pesar de reiterados intentos hasta compromisos previamente adquiridos no fueron realizadas un total de cinco, lo que al final nos dejó un resultado de quince entrevistas.

La muestra de informantes, su larga experiencia, amplia y larga trayectoria profesional, la variedad de responsabilidades desempeñadas, les hace conocedores del sistema de organización del entorno minero. Estas características nos aseguran una información amplia y diversa, que al proceder de fuentes variadas y complementarias, enriquecen la visión por nosotros pretendida, al igual que su diversidad en edades y funciones desempeñadas. En general los colectivos participantes se mostraron receptivos con el tema y muy conscientes de los cambios que se están produciendo en la sociedad y economía de la zona en el tiempo presente.

\section{UN ESPACIO GEOGRÁFICO MINERO SINGULAR}

La Sierra Minera de Cartagena-La Unión forma parte de un relieve externo que se extiende desde la ensenada del puerto de la ciudad de Cartagena hasta Cabo de Palos, abarca los municipios de Cartagena y La Unión. Está perfectamente delimitada al sur por el mar Mediterráneo, al este por el Mar Menor, al norte y oeste por el campo de Cartagena y los municipios de la Ribera del Mar Menor. El área delimitada para declarar esta zona como bien de interés cultural está basada en el impacto visual de los yacimientos mineros y demás elementos diseñados para la extracción y transporte del mineral.

FIGURA 3

El espacio geográfico de las sierras mineras de La Unión-Cartagena.

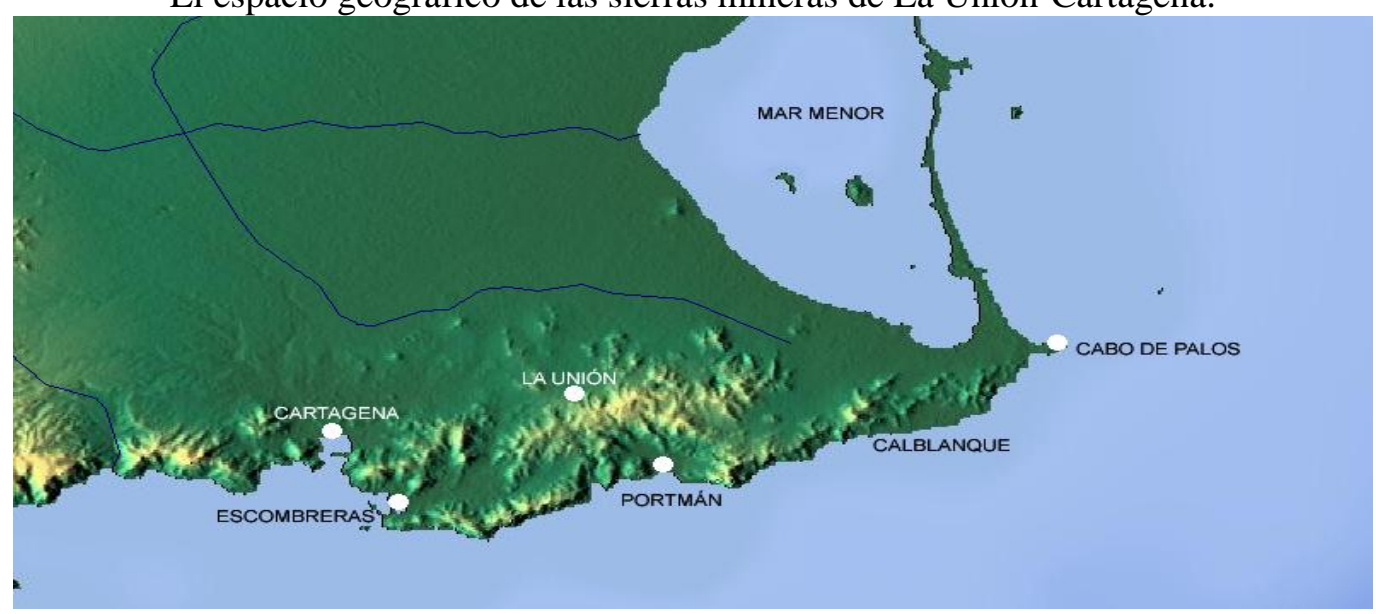

Fuente: www.Sierra-minera.png

Papeles de Geografía, 61 (2015), 77-96 
El desarrollo poblacional, es siempre un buen indicador en el avance económico de un espacio, generalmente a mayor desarrollo aumento de población y en periodo de crisis retrocesos o estancamientos, en relación a la evolución poblacional de los dos municipios y teniendo como base el año 1900, al comenzar el siglo XX observamos una gran disparidad en la evolución de ambos, mientras que el municipio de Cartagena ha duplicado ampliamente el número de habitantes pasando de 103.373 en 1900 a 216.451 en 2014; el municipio de La Unión ha perdido más de un tercio de su población pasando de los 30.275 en 1900 a 19.452 en 2014. En este tiempo Cartagena ha tenido una fase de estancamiento durante las tres primeras décadas (1900-1930) y una fase rápida de crecimiento a partir de los años 60, siendo espectacular el crecimiento en el siglo XXI.

En relación a La Unión salvo las dos primeras décadas del siglo XX en las cuales la población se mantuvo por encima de los 30.000 habitantes (GIL OLCINA, 1970), a partir de los años treinta se produjo una gran decadencia hasta la década de los años 50, las siguiente décadas ha existido una tímida recuperación, pero nada comparado con el esplendor de comienzos del siglo XX, de hecho en 1900 el ayuntamiento de La Unión era el cuarto en población total en la entonces provincia de Murcia tras la Capital -Murcia- (111.539), Cartagena (103.373) y Lorca (69.836), mientras que en el año 2013 ha pasado al puesto número dieciocho de los cuarenta y cinco existentes en la Región de Murcia, de hecho municipios limítrofes a La Unión que albergaban en el año 1900 una cifra muy pequeña: San Javier (4.489), San Pedro del Pinatar (2.647), Torre Pacheco (8.549), Fuente-Álamo (9.969), en 2013 el número se eleva en San Javier (32.366), San Pedro del Pinatar (24.093), Torre-Pacheco (33.218), Fuente-Álamo (15873) e incluso ha surgido en 1983 un nuevo ayuntamiento junto al Mar Menor, se trata de Los Alcázares que registra actualmente 16.217 habitantes.

TABLA 2

Evolución de la población de Cartagena y La Unión.

\begin{tabular}{|c|c|c|c|c|c|c|c|c|c|c|c|c|}
\hline & $\mathbf{1 9 0 0}$ & $\mathbf{1 9 1 0}$ & $\mathbf{1 9 2 0}$ & $\mathbf{1 9 3 0}$ & $\mathbf{1 9 4 0}$ & $\mathbf{1 9 5 0}$ & $\mathbf{1 9 6 0}$ & $\mathbf{1 9 7 0}$ & $\mathbf{1 9 8 1}$ & $\mathbf{1 9 9 1}$ & $\mathbf{2 0 0 1}$ & $\mathbf{2 0 1 4}$ \\
\hline $\begin{array}{c}\text { Carta- } \\
\text { gena }\end{array}$ & 103373 & 102542 & 101613 & 102705 & 115468 & 113160 & 123160 & 14690 & 172751 & 173061 & 184686 & 216451 \\
\hline $\begin{array}{c}\text { La } \\
\text { Unió } \\
\text { n }\end{array}$ & 30275 & 30249 & 24837 & 11776 & 10079 & 10131 & 11687 & 13145 & 14097 & 13732 & 14793 & 19452 \\
\hline
\end{tabular}

Fuente: Elaboración propia a partir de datos del INE

FIGURA 4

Evolución de la población de Cartagena.

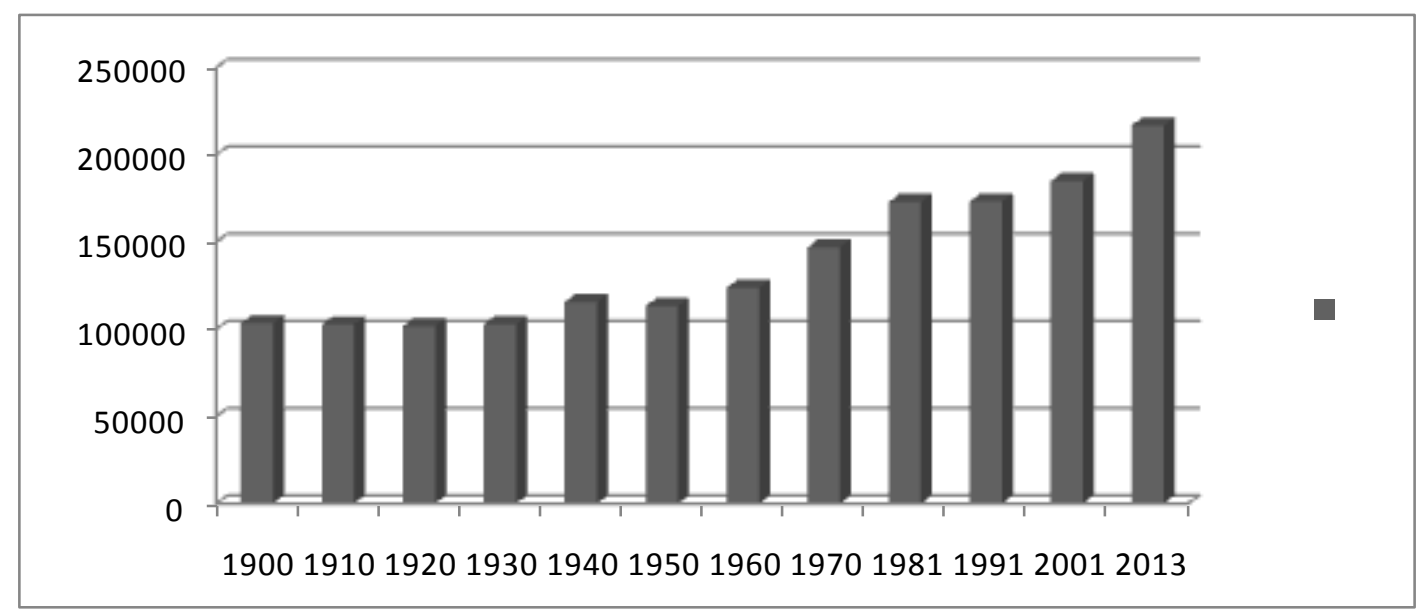

Fuente: Elaboración propia a partir de datos del INE 
FigURA 5

Evolución de la población de La Unión.

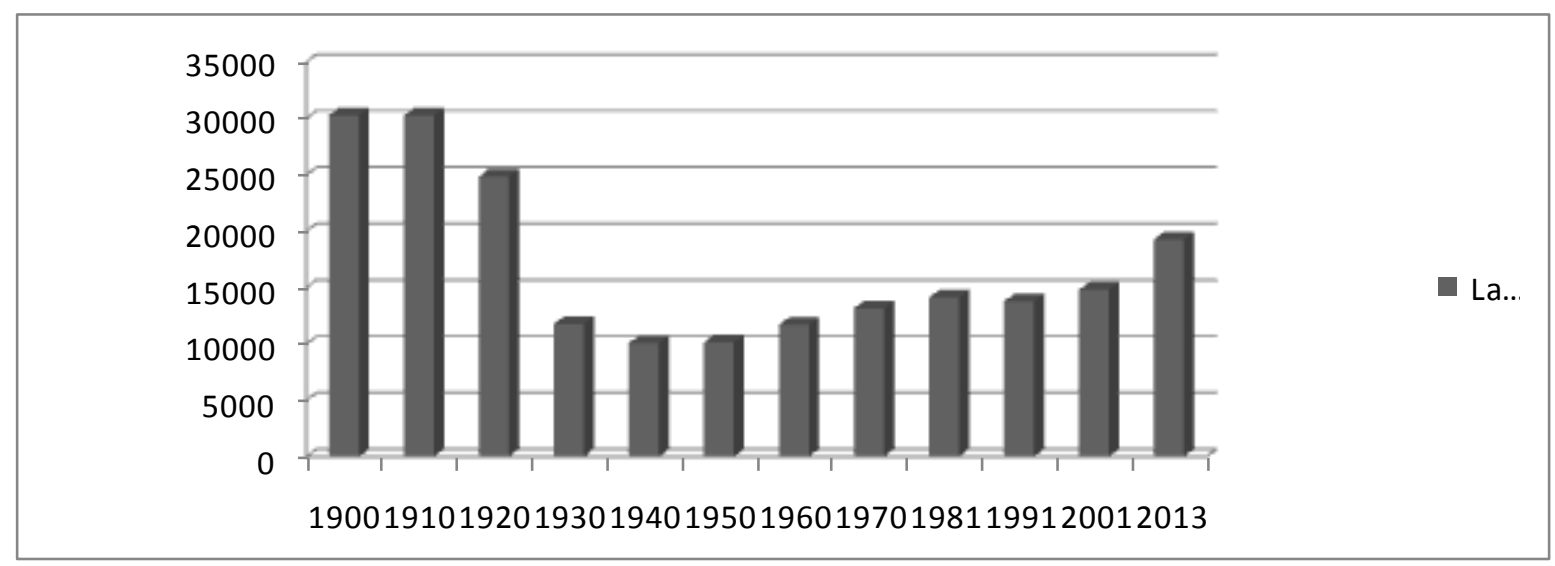

Fuente: Elaboración propia a partir de datos del INE

En relación a los usos del suelo de la comarca del Campo de Cartagena-La Unión se observa como el espacio minero ocupa la parte sureste, se encuentra muy localizada entre los términos municipales de las dos ciudades, en el caso del amplio municipio de Cartagena $\left(558,08 \mathrm{~km}^{2}\right)$ y el diminuto de La Unión $\left(24,6 \mathrm{Km}^{2}\right)$, gran parte del municipio de La Unión forma parte del parque minero, mientras que para Cartagena constituye menos del $1 \%$. A ello se añaden otros usos en creciente aumento como el residencial, bien para primeras residencias como también para residencias de veraneo, el agrario con una serie de cultivos extratempranos de gran productividad, esencialmente tras la llegada del agua a través de los canales del Taibilla debida a la puesta en funcionamiento del trasvase Tajo-Segura y finalmente usos industriales próximos a la ciudad de Cartagena (polígonos industriales Cabezo-Beaza, Los Camachos) y La Aljorra.

FIGURA 6

Usos del suelo de la Sierra Minera de La Unión-Cartagena.

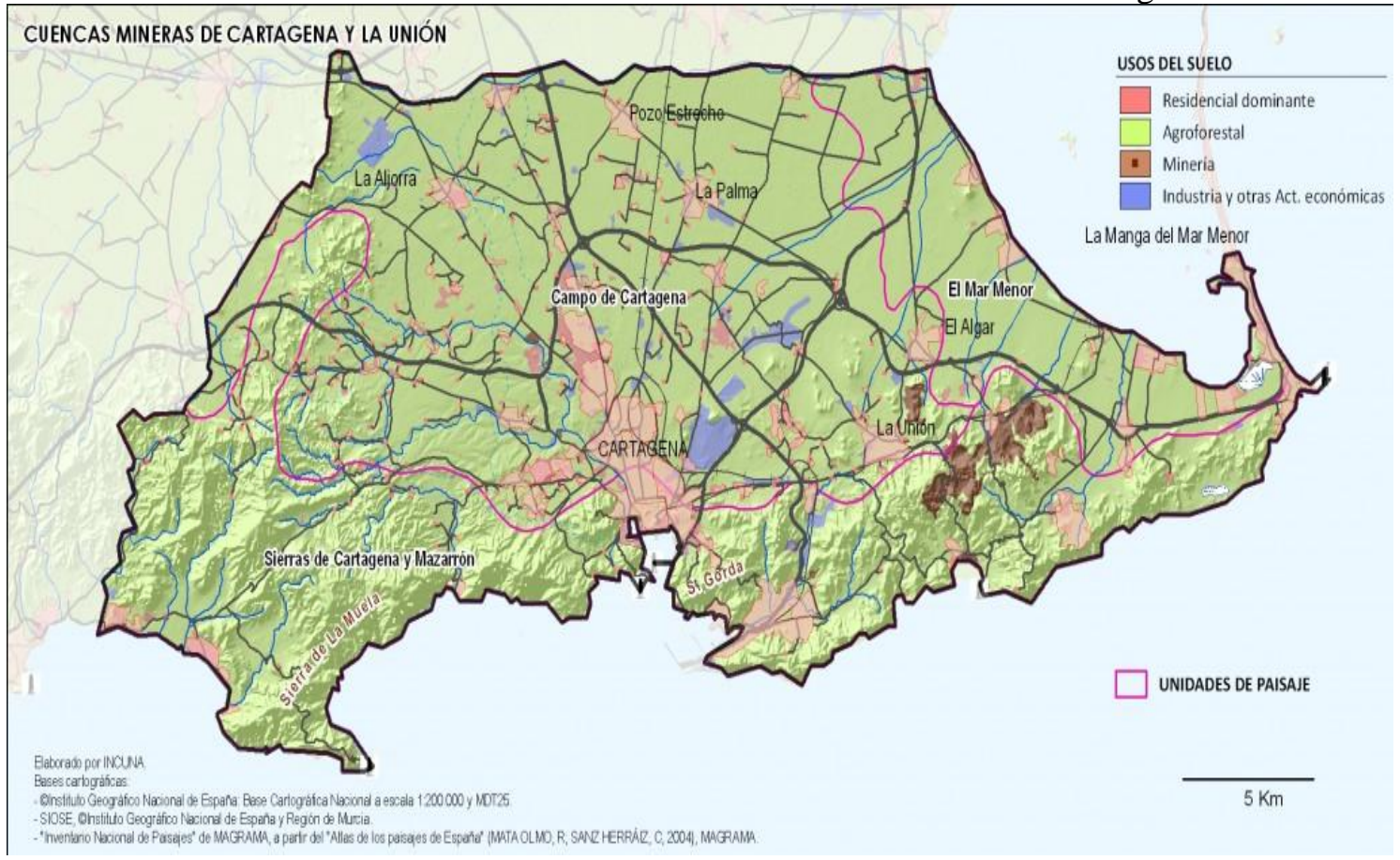

Fuente: Incuna. Asociación de Arqueología Industrial. Gijón (Asturias) 
La zona acotada como de "Bien de Interés Cultural" se encuentra organizada en ocho sectores, que presentan las siguientes características en cuanto a superficies, lo que significa un parque minero superior a las $1659 \mathrm{Ha}$ y un total de yacimientos arqueológicos y bienes muebles e inmuebles ubicados dentro de dicho perímetro de 267 e identificando entre otros: chimeneas, caminos mineros, fundiciones, lavaderos, túneles, polvorines, minados, castilletes, hornos de calcinación, minados, cortas y centros de transformación.

TABLA 3

Relación de sectores respecto a superficie y bienes que albergan.

\begin{tabular}{|l|l|r|r|}
\hline \multicolumn{1}{|c|}{$\mathbf{N}^{\mathbf{0}}$ sector } & \multicolumn{1}{|c|}{ Denominación } & \multicolumn{1}{|c|}{$\begin{array}{c}\text { Superficie en } \\
\mathbf{m}^{\mathbf{2}}\end{array}$} & $\begin{array}{c}\text { Yacimientos y } \\
\text { bienes }\end{array}$ \\
\hline Sector I & Cerro de La Parreta de Alumbre & 244.285 & 14 \\
\hline Sector II & Cabezo Rajao & 744.124 & 6 \\
\hline Sector III & Lo Tacón & 28.818 & 26 \\
\hline Sector IV & Llano del Beal y El Beal & 852.167 & 66 \\
\hline Sector V & Camino del 33 o Cuesta de La Lajas & 2.277 .560 & 99 \\
\hline Sector VI & $\begin{array}{l}\text { Rambla del Abenque y Cabezo de la } \\
\text { Galera }\end{array}$ & 2.865 .945 & 2 \\
\hline Sector VII & $\begin{array}{l}\text { Cabezo de Ponce, Peña del Aguila y } \\
\text { Monte de las Cenizas }\end{array}$ & 9.541 .961 & 267 \\
\hline Sector VIII & Lavadero Roberto de Portmán & 41.451 & \\
\hline Total & \multicolumn{1}{|c|}{} & 16.596 .311 & \\
\hline
\end{tabular}

Fuente: Elaboración propia a partir del Decreto de BIC

Una división más concreta de los yacimientos y bienes culturales podría hacerse a través de la nomenclatura que hace el inventario para la declaración de bien cultural, mencionamos los más destacados en los dos municipios, en números absolutos destacan las instalaciones minerometalúrgicas, en Cartagena sesenta y ocho; en La Unión seis, castilletes treinta en Cartagena y veintidós en La Unión, lavaderos uno en Cartagena y cinco en La Unión, hornos de calcificación cuatro en Cartagena y ocho en La Unión, tres túneles en Cartagena y dos en La Unión, cinco chimeneas en cada uno de ellos, también tres minados en cada unos de ellos y dieciséis lavaderos en Cartagena y diecisiete en La Unión.

Finalmente destacamos otras instalaciones como tres polvorines en Cartagena, cinco caminos mineros en Cartagena, un centro de transformación en Cartagena, tres fundiciones en La Unión; también son muy importantes los yacimientos de época romana: veintiuno en Cartagena y diecinueve en La Unión.

FigURA 7

Relación de inventario de bienes culturales.

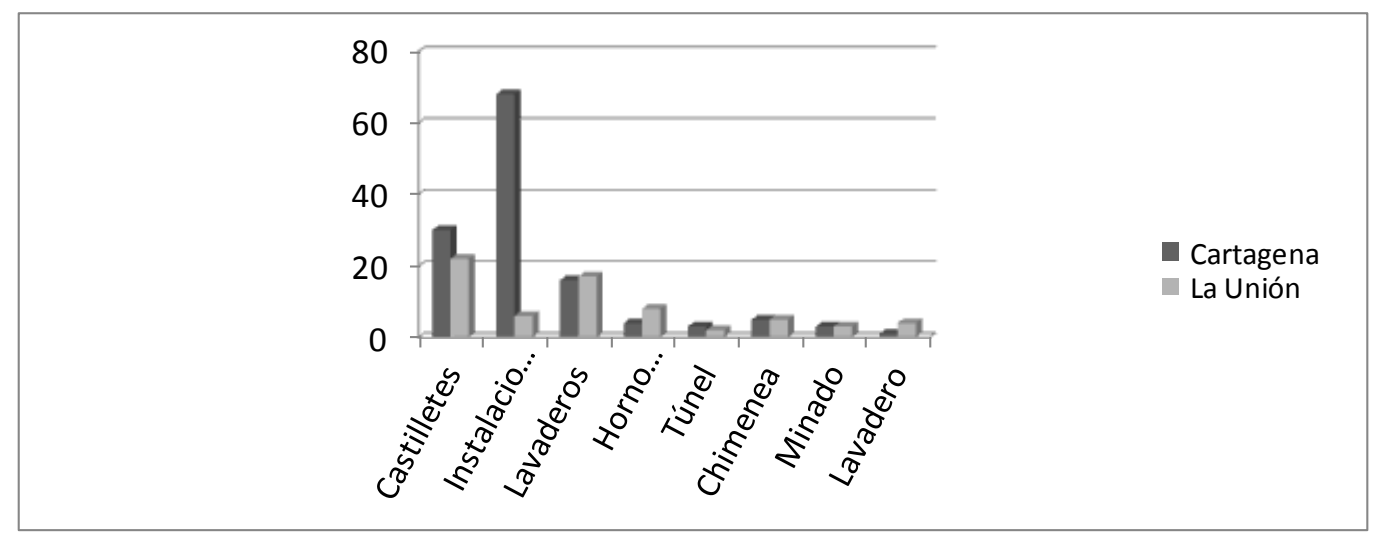

Fuente: Elaboración propia a partir del catálogo de BIC 
Desde época romana son célebres los yacimientos minerales de este espacio, de hecho el geógrafo Estrabón parafraseando a Polibio, describe la extensión las minas de plata de Carthago Nova.

"Polibio, al mencionar las minas de plata de Cartagena, dice que son muy grandes, que distan de la ciudad unos veinte estadios (unos cuatro kilómetros) que ocupan un área de unos cuatrocientos estadios (unos sesenta y cinco kilómetros), que en ellas trabajan cuarenta mil obreros y que en su tiempo reportaban al pueblo romano 25000 dracmas diarios. Y omito todo lo que cuenta del proceso del laboreo, porque es largo de contar, pero no lo que se refiere a la ganga argentífera arrastrada por una corriente, de la que, dice, se machaca y por medio de tamices se les separa del agua; los sedimentos son triturados de nuevo y nuevamente filtrados y, separadas así las aguas, machacados aún otra vez. Entonces, este quinto sedimento se funde y, separado el plomo, queda la plata pura. Actualmente las minas de plata están todavía en actividad; pero tanto aqui como en otros lugares, han dejado de ser públicas" ESTRABÓN, Geografía, Libro III

Debido al rápido desarrollo de la minería durante el siglo XIX, las corporaciones pedáneas de El Garbanzal, Herrerías, Roche y Portmán decidieron secesionarse de Cartagena a fin de fusionarse en municipio y ayuntamiento propios con el nombre de Villa de El Garbanzal, ello sucedió hacia 1 de enero de 1860), en esta época entre los cuatro poblados había 4916 almas (BELL ADELL, 1982). El puerto de Portmán que tenía uso desde época romana continúo siendo junto a la dársena de Cartagena y Escombreras los tres puertos más importantes para dar salida al abundante mineral generado en estas sierras. Sin embargo, pronto las desavenencias entre los pobladores de los principales caseríos (Garbanzal y Herrerías) condujeron al cambio de nombre del joven municipio, que pasaría a llamarse "La Unión" a partir de 1868. En 1894, la villa recibiría el título de ciudad. Una considerable inmigración de andaluces: almerienses, jienenses y granadinos, venidos a trabajar en las minas de la localidad, contribuyó al especial carácter etno-cultural de la ciudad, ciertamente afín al de la Andalucía oriental, esencialmente de la cercana provincia de Almería.

La actividad minera en las sierras de La Unión-Cartagena convirtió este espacio en un área especializada dedica a diferentes minerales como la plata y plomo en la antigüedad romana, zinc, hierro y otros minerales metálicos como la galena, la blenda, la pirita, la calcopirita y la magnetita; lo que dio origen en una primera fase a la realización de galerías subterráneas y en último periodo a la apertura de grandes minas a cielo abierto que provocaron graves impactos ambientales en este espacio y que lógicamente han pervivido hasta nuestros días. Durante dos milenios y $\sin$ apenas interrupciones la minería supuso un monocultivo económico según GARCÍA DELGADO, que se apagó finalmente con el cierre de la mina de Portmán en 1991. Fruto de esta evolución minera ha quedado un rico y variado patrimonio minero debido a la existencia de muchos yacimientos así como una variada arqueología industrial que se debate entre la degradación debida al abandono tras la desindustrialización y el intento de su puesta en valor como un recurso turístico novedoso y complementario al actual de Sol y Playa localizado en La Manga del Mar Menor y su entorno, al de tipo cultural en la ciudad de Cartagena o etnográfico en el núcleo urbano de La Unión.

Destacamos la puesta en valor de la Mina de Las Matildes (ANTOLINOS MARÍN, et AL, 2007) como una de las principales acción llevadas a cabo entre los años 2003-2005 bajo la denominación de proyecto "JARA", ha llevado a cabo la rehabilitación completa de sus edificaciones y de su castillete, utilizando criterios de respeto y realce de estos elementos mineros como bienes de interés cultural, y contemplando en la restauración de los edificios medidas de ahorro energético y utilización de energía solar. Dichas acciones eran resumidas en la memoria al respecto: 
TABLA 4

Acciones puesta en valor de la Mina Las Matildas.

- Se ha rehabilitado como espacio principal del centro una nave amplia vacía, que correspondió a una primera sala de máquinas de la etapa inicial de explotación minera. En ella se han descubierto los basamentos y conducciones de la primitiva maquinaria de vapor, como vestigios de arqueología industrial de gran interés.

- Se ha restaurado su castillete metálico y habilitado el acceso hasta su pozo de $225 \mathrm{~m}$ de profundidad, en condiciones de seguridad.

- Se ha rehabilitado la segunda sala de máquinas destinada a la extracción de agua a principios del siglo XX, restaurando la maquinaria eléctrica que conservaba.

- Se ha acondicionado también la antigua balsa y restaurado otras dependencias anexas, como almacén y aseos.

Tras la rehabilitación de la Mina Las Matildes, se realizó una labor de musealización para reconvertirla en un moderno Centro de Interpretación de la Minería y el Medio Ambiente de la Sierra Minera y, en particular, de la especificidad de las minas del entorno del Beal dedicadas al desagüe de la cuenca minera. A través de paneles interpretativos, una maqueta de la sierra, juegos didácticos y proyecciones audiovisuales en 3D, la mina Las Matildes se ha reconvertido en un espacio interpretativo en el que poder conocer de una forma didáctica y amena, distintas facetas de la minería y de las huellas que ha dejado en el medio ambiente y en la idiosincrasia de esta comarca.

- En el propio centro se ha puesto en marcha un servicio integrado de ecoturismo y turismo cultural, con una oferta amplia de itinerarios guiados en el conjunto de la sierra.

- Se ha realizado también una labor inicial de promoción y difusión de esta nueva oferta cultural en centros escolares, asociaciones y entidades de la región, sector hostelero y turístico, medios de comunicación, etc., potenciando una imagen de producto turístico diferenciado y de marcado carácter ecocultural.

Fuente: ANTOLINOS MARÍN, J.A.y PEÑAS CASTEJÓN, JOSÉ MATÍAS (2007) "Catalogación del patrimonio cultural en la sierra minera de Cartagena-La Unión",

FIGURAS 8 y 9

Mina de Las Matildes (Llano del Beal).Detalles de la puesta en valor.
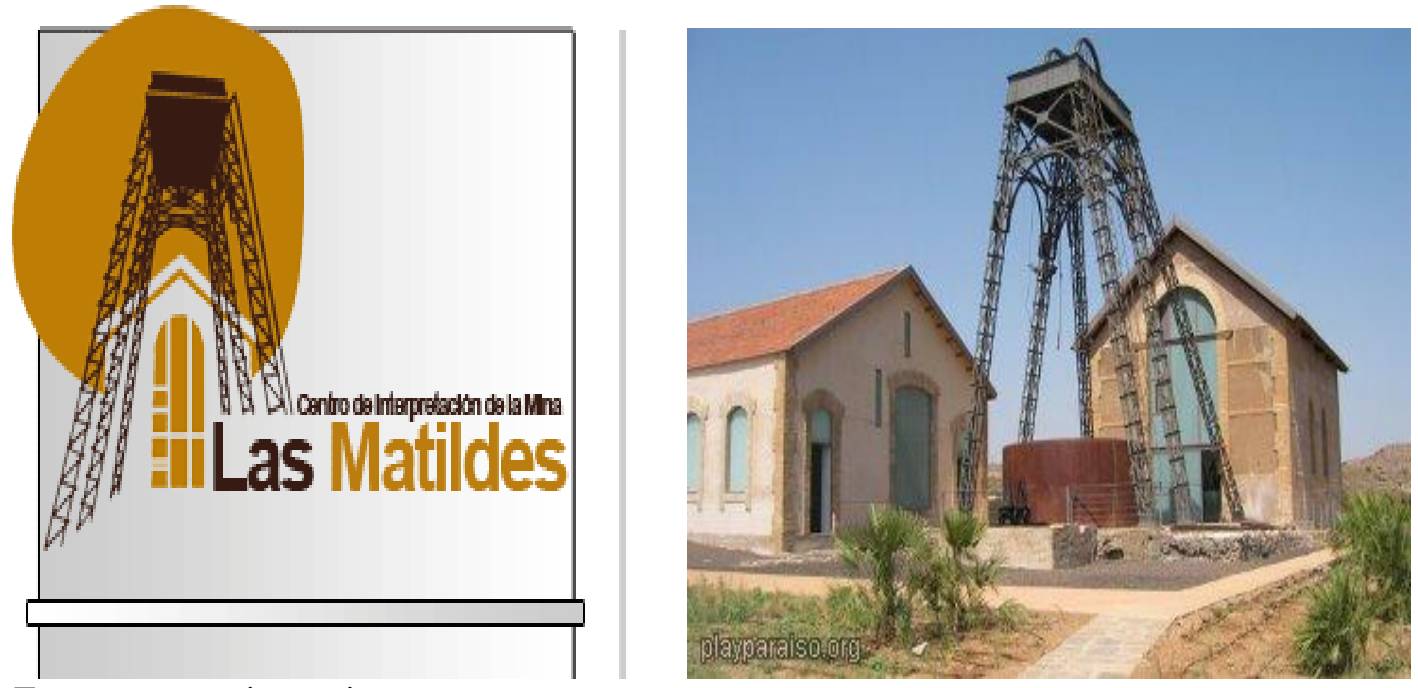

Fuente: www.sierraminera.org

\section{RESULTADOS DE LA METODOLOGÍA DE ANÁLISIS D.A.F.O.}

El análisis DAFO (Debilidades, Amenazas, Fortalezas, Oportunidades) es una herramienta que nos dará un diagnóstico sobre el estado de este espacio de La Unión-Cartagena tanto a 
nivel interno como externo. Tendremos en cuenta aquellas amenazas u oportunidades que vienen de fuera, así como las carencias o fortalezas que van apareciendo. De la combinación de fortalezas con oportunidades surgen las potencialidades, las cuales señalan las líneas de acción más prometedoras para la mejora integral de este espacio. Mientras que la combinación de debilidades y amenazas, nos advertirán de los riesgos y los desafíos a corto y medio plazo. En este sentido las autoridades políticas y colectivos sociales señalan las actuaciones para la mejora de la oferta turística. Indicamos a continuación de forma sintética los puntos más destacados del análisis efectuado.

\subsection{Debilidades}

-Se percibe que el proceso de recuperación y puesta en valor del patrimonio minero es lenta esencialmente en la recuperación de edificios y maquinaria industrial.

-Ha existido una escasa conciencia colectiva sobre los valores culturales, turísticos y medioambientales que supone la recuperación de este espacio.

-El abandono y deterioro progresivo de los bienes de conservación complica la rehabilitación, ya que se trata de inversiones muy costosas.

-El impacto visual de las instalaciones con un aspecto tan degradado genera una estética decadente del territorio lo que repercute en la falta de inversiones por parte de la iniciativa privada.

-El proyecto de recuperación de la Bahía de Portmán está siendo muy lento, de hecho tras treinta años se ha previsto para 2015 el comienzo de esta regeneración.

-Es necesario armonizar el turismo existe de playas, por ejemplo Calblanque, con la puesta en valor y difusión del patrimonio natural, arquitectónico, arqueológico, e industrial.

-La promoción como destino turístico todavía es pequeña, comparada con otras ofertas de la zona: turismo náutico, pesca submarina, "Cartagena, puerto de Culturas", etc.

-La oferta hotelera de la zona está totalmente enfocada al turismo de Sol y Playa, también al golf y actividades náuticas.

--Insuficientes acciones de investigación, conservación y museización del patrimonio arquitectónico, etnográfico e industrial

-Falta de profesionalidad en el personal de base en la restauración procedente de la minería y oferta formativa en hostelería en la Comarca y gastronomía local.

-El potencial turístico del municipio de La Unión es todavía muy incipiente.

-Se debe mejorar la señalización de los lugares, desde las autovías próximas no se indica este destino turístico de forma contundente.

FIGURA 10

Bahía de Portmán en la actualidad cubierta de residuos estériles.

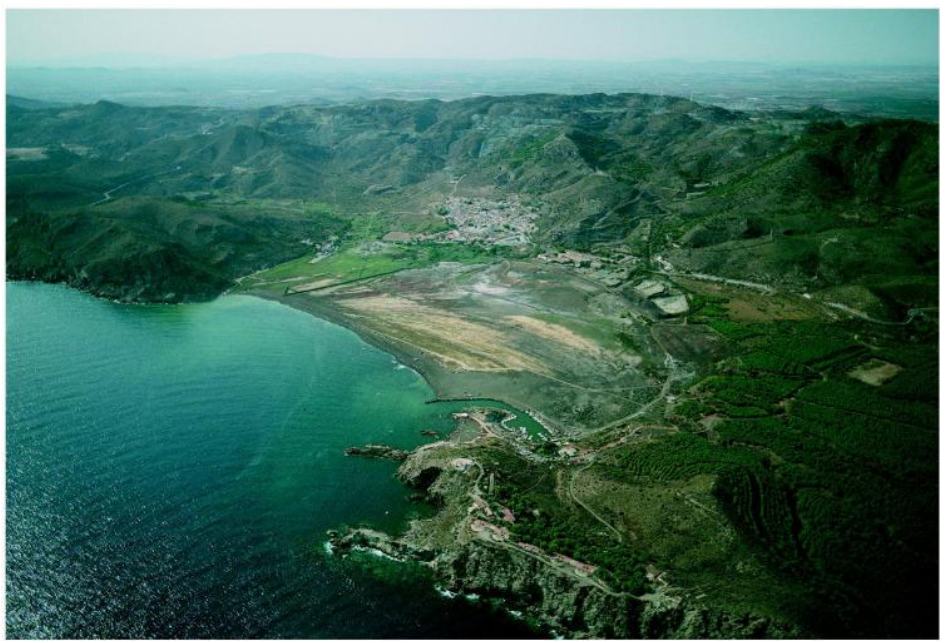

Fuente:www.taringa.es

Papeles de Geografía, 61 (2015), 77-96 


\subsection{Amenazas}

-La actual crisis económica debida a la burbuja inmobiliaria y falta de financiación ha derivado en la paralización de proyectos necesarios

-La ausencia de una estructura organizativa supramunicipal puede impedir la ejecución de algunas actuaciones al no conciliar la presencia de Ayuntamientos, propietarios e inversores, se debe llegar a un trabajo coordinado entre los ayuntamientos de Cartagena y La Unión.

-La oferta turística de la zona como turismo de Sol y Playa oscurece la potencialidad que tiene el turismo industrial-minero.

-El patrimonio continúa desapareciendo y cada vez más deteriorado, lo que significa una pérdida irreparable de las potencialidades existentes, por ejemplo Las Minas La Cierva y Lo Veremos Viejo en el entorno del casco urbano de La Unión han sufrido un gravísimo atentado con la desaparición de las máquinas de extracción de ambas minas, además del destrozo del conjunto de elementos de la maquinaria no metálica y del foso de obra. Las máquinas de hierro, previsiblemente robadas, pesaban varias toneladas cada una, y estaban dotadas de un gran eje, poleas, volantes y ruedas de engranaje de unos tres metros de diámetro, así como cintas de acero y otros elementos. Estaban instaladas sobre un gran foso en el interior de las salas de máquinas, junto a los respectivos castilletes. Las máquinas, han debido ser desguazadas y troceadas en múltiples fragmentos para poder sacarlas de los edificios donde estaban, habiendo sido destrozadas las paredes de los fosos, así como las grandes vigas de madera de pino de Canadá sobre las que se asentaban. El desmantelamiento de las máquinas ha debido requerir mucho tiempo, así como vehículos y herramientas, siendo inexplicable que se haya podido perpetrar semejante expolio en las proximidades del casco urbano sin que haya sido detectado (Asociación ADEPA. 12/12/2013)

-La Región de Murcia presenta destinos culturales que continúan creciendo, el más próximo es Cartagena, aunque también Murcia quedad muy cerca, también destacamos Lorca, Caravaca o las rutas del vino del Altiplano.

-Riesgo de que el desarrollo del producto "sol y playa" derive en un turismo residencial si no se realiza un fuerte control urbanístico sobre los nuevos desarrollos, por ejemplo los resort en campos de Golf, Polaris World, etc.

\subsection{Fortalezas}

- Declaración de Bien de interés cultural por el Consejo de gobierno de la Comunidad Autónoma de Murcia (decreto n ${ }^{\circ}$ 93/2009, de 30 de abril)

-Iniciativas recientes para la constitución del Consorcio Turístico que refleja el interés del sector privado en la gestión turística

-Existe un constante flujo de iniciativas que están mejorando este espacio y poniéndolo en valor.

- Comunicación fluida entre la Administración Local y Regional

- Labor realizada por la Fundación Sierra Minera en la investigación y puesta en valor del patrimonio.

- Accesibilidad de La Unión y Portmán (proximidad al Hyatt)

- Disponibilidad de elementos mineros de gran interés para su puesta en valor: transporte ferroviario, calzada romana, pasadizos y túneles, puerto, etc.

- Playas con bajo grado de urbanización y masificación, debido esencialemente al control de los accesos, por ejemplo Calblanque.

- Variedad y riqueza de los recursos naturales (bien conservados), arqueológicos (paleolítico, fenicio, romano), etnográfico-minero (oficios, gastronomía), arquitectónicos (Casa del Piñón, Casa Tío Lobo, Liceo de Trabajadores...), arqueológico minero

-El festival del Cante de las Minas es un elemento cultural que se debe seguir promocionado por su singularidad y atractivo internacional.

- Buena conservación de parte del patrimonio arquitectónico, listo para ser visitado: Museo Minero, Hospital de la Caridad 
- Oferta de bares y tabernas, herencia del esplendor minero

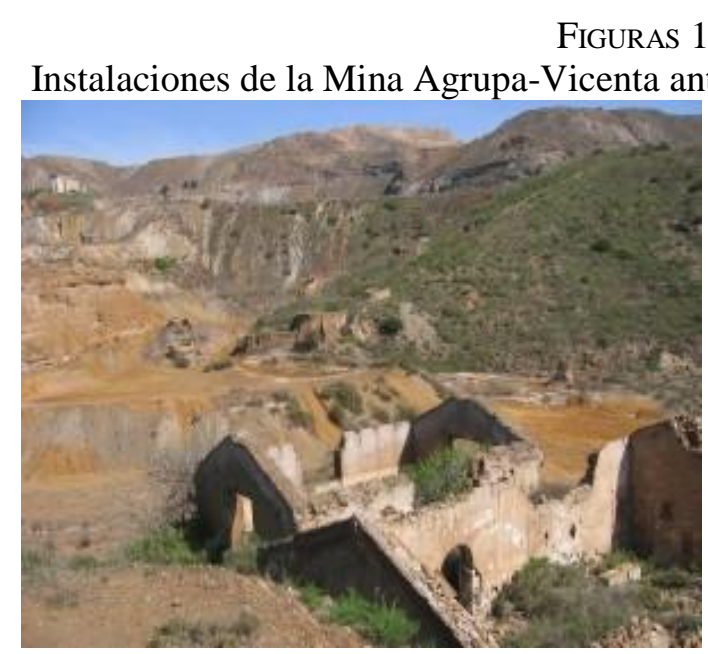

Fuente: sierraminera.org después de la rehabilitación

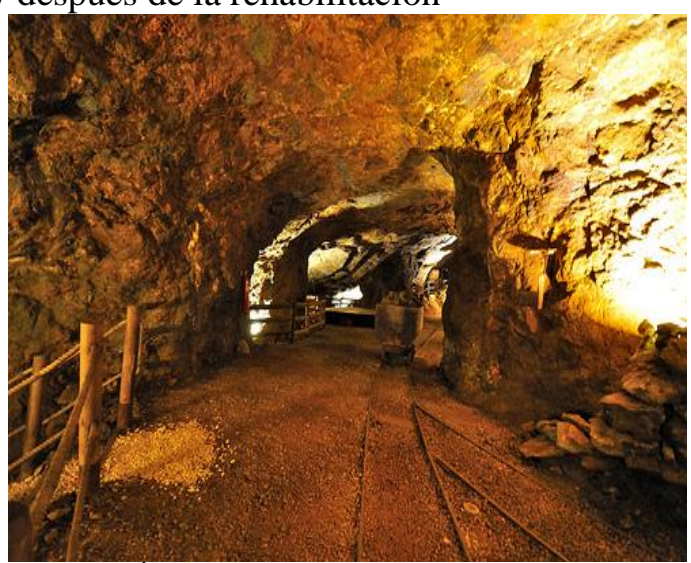

Fuente: Álvarez, M.A.

\subsection{Oportunidades}

- La puesta en marcha del convenio Europeo del Paisaje (2000) en España a partir del 2008 supone una gran iniciativa en la obtención de subvenciones y fondos para la puesta en marcha de los paisajes mineros, destacamos los planes: PRODER, LIFE...

-La declaración de Bien de Interés Cultural como sitio Histórico de la Sierra Minera de La Unión-Cartagena (2009) constituye un gran hito para la valoración de este espacio.

-El tradicional turismo de Sol y Playa, náutico de La Manga, así como el cultural proveniente de la ciudad de Cartagena adquieren una gran potencialidad para aumentar el número de viajeros.

-La proximidad del complejo de Golf Hyatt puede garantizar la afluencia de visitantes para la puesta en valor de los recursos mineros

-La regeneración de este espacio ha elegido emplear la técnica de la fitorrecuperación con plantas compatibles con los metales contaminantes contenidos en el suelo (CASTAÑEDA LÒPEZ, 2013)

En la situación actual es difícil, pero los entrevistados afirman en la necesidad de seguir potenciando la actividad del parque minero, favorecer acuerdos entre todas los agentes implicados (restaurantes, alojamientos, tiendas especializadas, AA.VV., ayuntamientos y entidades supralocales), al objeto de favorecer mayores sinergias. También se incide en mejorar la señalética y en establecer actividades y acciones de visibilidad y sensibilización sobre aspectos vinculados a la actividad de visita y museística. Además, los datos obtenidos han dado una visión aproximada y real, más allá de las estadísticas, de la actual situación del sector. Salvo excepciones la participación de los encuestados ha sido plena. Esperamos que los resultados obtenidos anteriormente, puedan servir de referencia como un análisis actual y de proyección futura.

\section{UNA ACTIVIDAD TURÍSTICA CRECIENTE}

Los datos estadísticos suministrados por la Oficina de Turismo de La Unión y la institución Parque Minero de La Unión, señalan un importante incremento de las visitas al municipio. Aunque los datos son bastante recientes ya que hasta hace poco no había ninguna recogida de datos porque la actividad turística era casi inexistente. En el Parque Minero tenemos cifras del último cuarto del año 2012 en donde se registran un total de 10.012 visitas, durante todo el año 2013 las visitas alcanzan la cifra de 27329 , destacado el mes de marzo con 4668 con una regularidad a lo largo de todo el año, lo cual indica la baja estacionalidad de esta actividad 
turística. Finalmente en 2014 los datos de visitas al parque minero llegan a las 27749, destacando el mes de abril con 3823 visitas y en segundo lugar agosto con 3031 . Aunque se mantiene un ritmo regular de visitas a lo largo del año, tal como indican las cifras el mes en que cae la semana santa (marzo en 2013 y abril en 2014) y agosto son los meses de mayor afluencia, lo que coincide con el periodo vacacional habitual de la mayor parte de la población de nuestro país.

\section{COMPARATIVO VISITAS AÑOS 2013 - 2014}

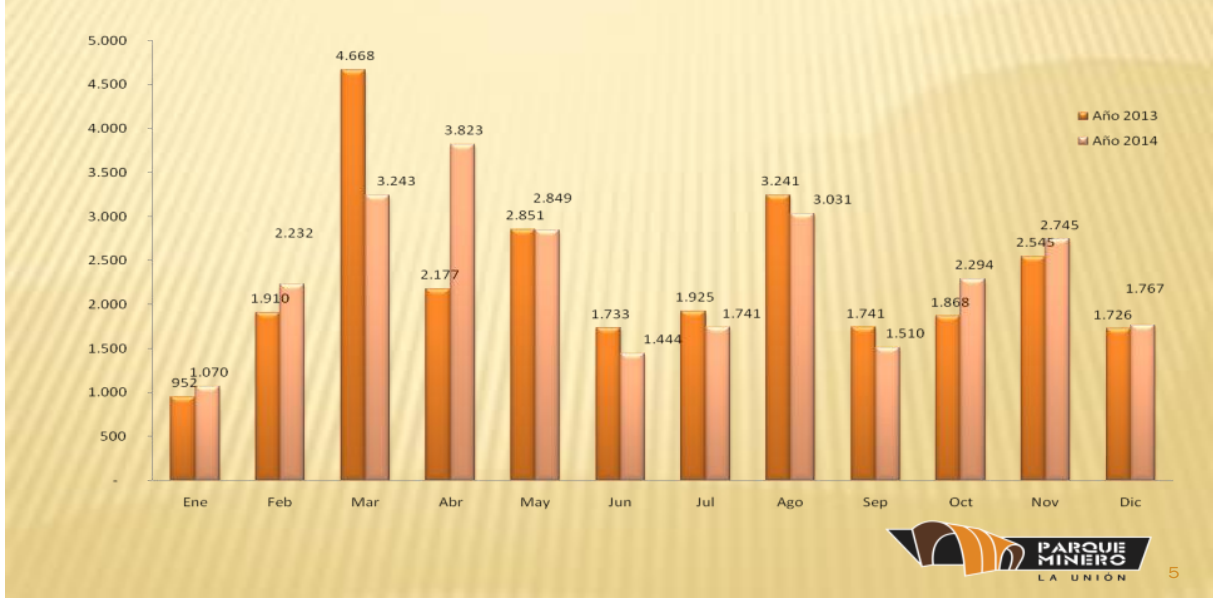

Fuente: Parque minero de La Unión

En relación al municipio de Cartagena, destacamos como un importante factor en el crecimiento turístico la modalidad del "Turismo de cruceros", de hecho turismo de cruceros es habitual que se produzca en fines de semana y meses menos veraniegos como serían marzo, octubre o noviembre, lo que ayuda a diversificar la economía y romper con la típica estacionalidad de los espacios litorales. La cuestión todavía por promocionar es la visita de los cruceristas al Parque Minero de forma masiva, la mayor parte de los visitantes aprovechan la estancia para visitar la ciudad de Cartagena o hacer compras en establecimientos comerciales como Parque Mediterráneo.

FIGURA 14

Previsión llegada de Cruceros al puerto de Cartagena en 2015.

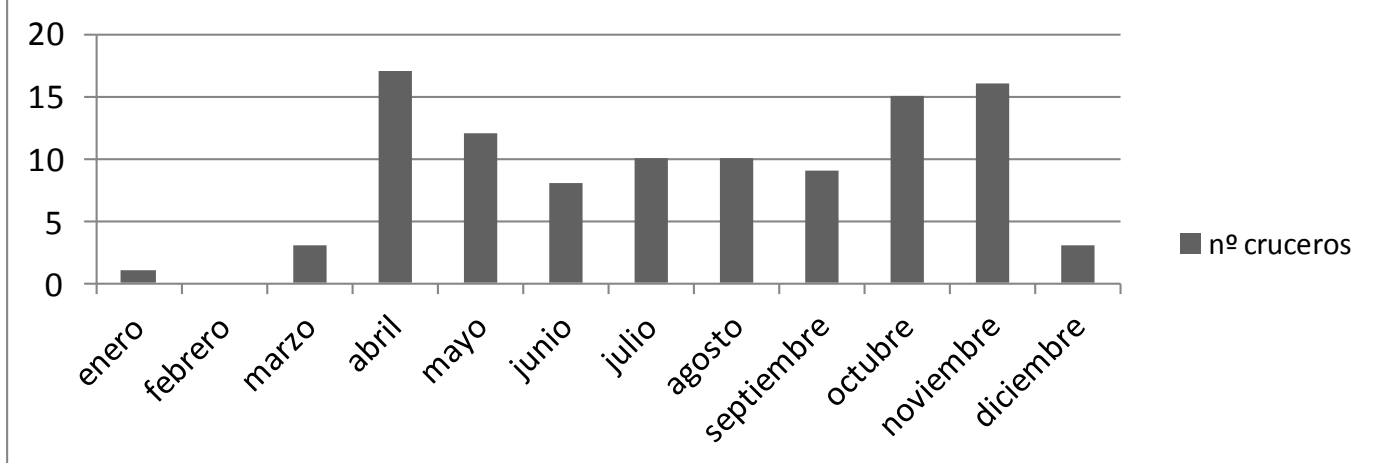

Fuente: Autoridad portuaria de Cartagena 


\section{A MODO DE CONCLUSIÓN}

La sierra minera de La Unión-Cartagena está localizada en un espacio de gran relevancia económica. Las condiciones de puesta en valor como la regeneración de la bahía de Portmán, mejora de accesibilidad, realización de grandes inversiones para recuperar el patrimonio industrial suponen actuaciones difíciles en los tiempos actuales ya que el recorte en subvenciones y partidas presupuestarias frena este proceso. Hasta hace pocas fechas, había una gran expulsión de la población autóctona, de hecho el municipio de La Unión ha perdido más de un tercio de su población en el último siglo debido esencialmente al cese de actividad en las minas.

Ante ello señalamos una serie de propuestas que podrían incentivar una dinámica creciente en el desarrollo de este espacio:

1. Implicar de forma activa y conjunta a instituciones públicas y privadas en los proyecto de puesta en valor y rehabilitación del patrimonio. Hasta el presente la mayoría de las inversiones han sido realizadas por instituciones públicas a través de fondos europeos, estales, regionales y municipales. Evidentemente salvo fundaciones privadas no existe aportación de capital privado a no ser que haya detrás un beneficio a corto-medio plazo, por ejemplo en operaciones inmobiliarias que actualmente son poco viables.

2. Diseñar una amplia oferta cultural de visitas y talleres que esté perfectamente difundida y conocida por tour operadores, por ello es necesaria una permanente conexión con la oferta desarrollada en la Manga del Mar Menor.

3. Es imprescindible un trabajo mucho más coordinado entre los ayuntamientos de La Unión-Cartagena para generar sinergias de actividades conjuntas, aunque existe una creciente colaboración todavía es necesaria un mayor nivel de desarrollo y mancomunar servicios turísticos.

4. La oferta hotelera y gastronómica en La Unión necesita aumentarse, dentro del parque minero es inexistente.

5. La sensación de grandes espacios baldíos a modo de eriales sociales está muy presente, todavía las rehabilitaciones han sido escasas en relación al conjunto de toda la superficie del parque minero, ello aporta sensación de abandono.

6. El expolio y destrucción del patrimonio continúan produciéndose sistemáticamente, gran parte de la maquinaria es destinada directamente como residuo industrial para ser reciclada como chatarra, esencialmente los antiguos motores y estructuras metálicas que tienen un importante valor etnográfico.

7. Es urgente la regeneración de la bahía de Portmán como lugar estratégico para el turismo, actualmente la actividad turística es inexistente. Este espacio tiene una gran potencialidad para dicha función y se encuentra ubicado dentro del propio parque minero, de hecho forma parte de él ya que fue uno de los lugares de salida del producto a través de su puerto.

8. La señalización y los accesos al parque minero deben incrementarse, a través de vallas publicitarias, rotulación y otros instrumentos de publicidad con la finalidad debe ser facilitar al visitante un fácil acceso así como la promoción y difusión del producto turístico, es básico que a través de la autovía de acceso a la Manga y las demás vías colindantes como las autovías Cartagena-Murcia-Madrid; Alicante-Cartagena-Vera puedan ofrecer publicidad de los atractivos que supone la visita a la Sierra minera de La Unión-Cartagena.

9. La presencia en las redes sociales de la oferta cultural, educativa y turística del parque minero es todavía insuficiente, las páginas web existentes debe ser actualizadas y mejoradas constantemente.

10. Es preciso fomentar una mayor concienciación entre la población sobre el importante patrimonio que posee el parque minero, todas las iniciativas que puedan dar una mayor 
difusión son imprescindibles, tanto institucionales como de asociaciones culturales, de vecinos o iniciativas individuales.

\section{BIBLIOGRAFÍA}

ADEPA.http://www.adepa-patrimonio.org/index.php/temas-de-patrimonio histórico/patrimoniominero [consulta: 15-01-2015].

ANDRÉS SARASA, J. L.(1998) “¿Cuencas mineras en crisis versus destinos turísticos?” Papeles de Geografía, no 27, pp. 5-14.

ANTOLINOS MARÍN, J.A. y PEÑAS CASTEJÓN, JOSÉ MATÍAS (2007) “Catalogación del patrimonio cultural en la sierra minera de Cartagena-La Unión”, pp. 327-416

BELL ADELL, C. (1982) Población y Recursos humanos de la Región de Murcia. Biblioteca básica murciana, $\mathrm{n}^{\circ} 12$.

BENITO DEL POZO, P. (2002): "Patrimonio industrial y cultura del territorio", Boletín de la Asociación de Geógrafos Españoles, n ${ }^{\circ} 34$, pp. 213-227.

CAÑIZARES RUIZ, M.C. (2011) "Patrimonio, parques mineros y turismo en España" Cuadernos de Turismo, $\mathrm{n}^{\circ}$ 27; pp. 133-153.

CAÑIZARES RUIZ, M.C. (2011): "Protección y defensa del patrimonio Minero en España", Scripta Nova, Vol. XV, n 361, en http://www.ub.es/geocrit/sn/sn-361.htm [consulta: 11-042014].

CARCELÉN GONZÁLEZ., R (2013) "Proyecto de recuperación del arsenal de Cartagena". Incuna. Gijón (Asturias) pp. 715-722

CASANELLES, E y FERNÁNDEZ, M. (1994) "Un modelo para trabajar el patrimonio industrial", en El Patrimonio Histórico artístico. Barcelona. Graó Educación.

CASTAÑEDA LÓPEZ, C (2013) "Iniciativas de recuperación en el patrimonio minero y regeneración medioambiental”. Incuna. Gijón (Asturias). pp. 375-381

CONSEJERÍA DE TURISMO Y ORDENACIÓN DEL TERRITORIO DE LA REGIÓN DE MURCIA (2004) Plan de dinamización turística de la Sierra Minera de La Unión-Cartagena. Documento de síntesis. $16 \mathrm{pp}$.

http://www.murciaturistica.es/PORTAL2002/sectorturistico/pdf/Final\%20sierra\%20minera\%20 la\%20union-cartagena.pdf [consulta: 15-01-2015]

(2009) Atlas de los paisajes de la Región de Murcia. Murcia, 234 páginas.

CONSEJERÍA DE TURISMO Y ORDENACIÓN DEL TERRITORIO DE LA REGIÓN DE MURCIA (2004) Plan de dinamización turística de la Sierra Minera de La Unión-Cartagena. Documento de síntesis. 16 pp.

http://www.murciaturistica.es/PORTAL2002/sectorturistico/pdf/Final\%20sierra\%20minera\%20 la\%20union-cartagena.pdf [consulta 15-01-2015]

CONSEJERÍA DE OBRAS PÚBLICAS Y ORDENACIÓN DEL TERRITORIO (2009) Atlas de los paisajes de la Región de Murcia. Murcia. 234 pp.

GARCÍA DELGADO, F.J. y Otros (2013) "El turismo en la cuenca minera de Ríotinto" Cuadernos de Turismo, $\mathrm{n}^{\circ} 31$; pp. 129-152.

GIL OLCINA, A. "Evolución demográfica del municipio minero de La Unión" en dialnet.unirioja.es/descarga/articulo/2296099.pdf [consulta 10-03-2015]

HUDSON, K. (1983) The archaeology of the consumer society: the second industrial revolution in Britain. Londres. Heinemann

LLURDÉS I COIT, J.C. (1994) "El turismo industrial y la estética de los paisajes en declive". Estudios Turísticos, n. ${ }^{\circ} 121$. pp. 91-107.

LLURDÉS I COIT, J.C. (1997) "El turismo de patrimonio industrial y minero. Una experiencia de turismo interior inexplorada en estado español" Ediciones de la UAM.

LLURDÉS I COIT, J.C. (1999) "Patrimonio industrial y patrimonio de la humanidad. El ejemplo de las colonias textiles catalanas. Potencialidades turísticas y algunas reflexiones. Boletín de la $A G E, \mathrm{n}^{\circ} 28$, pp. 155-176. 
MARTÍNEZ, A. y PÉREZ, D. (1998) "El patrimonio industrial de la provincia de Alicante. Rehabilitación y nuevos usos". Investigaciones geográficas, no 19, pp. 49-66.

MORALES YAGO, F.J (2013). "El impacto de la actividad turística sobre el paisaje de La Manga del Mar Menor (Murcia)". Estudios Geográficos, no 57, pp.523-556.

PARDO ABAD, C.J. (2008): Turismo y patrimonio industrial. Madrid, Síntesis.

PARDO ABAD, C.J. (2010): "El patrimonio industrial en España: análisis turístico y significado territorial de algunos proyectos de recuperación", Boletín de la Asociación de Geógrafos Españoles, nº 53, pp. 239-264.

PARDO ABAD, C.J. (2011): Paisajes industriales e industrias para el turismo: simbolismo patrimonial y alcance territorial. Rotur Revista Ocio y Turismo, no 4, pp. 15-32.

PRAT I FORGA, J.M. (2014) "La generación de capital social alrededor del turismo industrial en destinos de Cataluña y Escocia”. Geographos. Vol. $5 \mathrm{n}^{\circ}$ 58. pp. 47-69 (http://web.ua.es/revista-geographos-giecryal) [consulta 11-03-2015]

VALENZUELA RUBIO, M y Otros (2008) "La valorización turística del patrimonio minero en entornos rurales desfavorecidos. Actores y experiencias". Cuadernos de Turismo, $\mathrm{n}^{\circ}$ 22; pp. 231-260.

ANEXO I.

LISTADO DE PREGUNTAS REALIZADAS EN LAS ENTREVISTAS A PERSONAS RELEVANTES EN ASPECTOS RELACIONADOS CON EL TURISMO MINERO EN LOS MUNICIPIOS DE LA UNIÓN-CARTAGENA

$1^{\circ}$ ¿Cuál es a su juicio, la valoración global de la calidad turística de la ruta minera de La UniónCartagena?. Trate de calificarla como "muy buena, buena, aceptable, regular, mala"

$2^{\circ}$ En relación a la pregunta anterior: cuando ha emitido tal valoración. ¿En qué aspectos concretos ha pensado o tenido en cuenta?

$3^{\circ}$ ¿Cuáles son los aspectos más necesitados de una mejora urgente? ¿Cuáles serían dentro de estos aspectos lo más difíciles para poner en funcionamiento? Le rogamos justifique su respuesta.

$4^{\circ}$ A continuación le pedimos lleve a cabo un análisis D.A.F.O. sobre la Gestión e Imagen que tiene la oferta turística minera de La Unión-Cartagena según su criterio personal. Señale en forma de frases cortas los siguientes aspectos: 


\begin{tabular}{|c|c|}
\hline DEBILIDADES & FORTALEZAS \\
\hline & \\
\hline AMENAZAS & OPORTUNIDADES \\
\hline & \\
\hline
\end{tabular}

$5^{\circ}$ Finalmente, le pedimos realice algún comentario que entienda no se le haya formulado para la valoración actual y mejora de la Ruta Minera de los municipios de La Unión-Cartagena. 